\title{
What risks do herbal products pose to the Australian community?
}

\author{
Roger W Byard', Ian Musgrave', Garth Maker², Michael Bunce ${ }^{3}$
}

$\mathrm{H}$ erbal medicines are plant-derived materials and preparations consumed for their presumed therapeutic or other health benefits. They may consist of raw materials such as bark, roots, leaves and seeds, or include processed ingredients in capsules or tablets, teas, or powders. Some herbal preparations may also contain declared or undeclared products derived from endangered animals, such as the snow leopard. ${ }^{1}$

Unfortunately, some herbal products are problematic in terms of their ingredients, effects and interactions with prescription medications. Complications associated with "non-medically qualified healers, lack of product standards, undeclared ingredients, nondisclosure of usage and long-term medication" have been identified. ${ }^{2}$ A survey of naturopaths and Western herbalists in Australia has, however, revealed support for formal registration and for evidence-based practice. ${ }^{3}$ A report published in 2016 detailed the potentially serious side effects of herbal dietary supplements, such as sub-massive hepatic necrosis necessitating organ transplantation caused by ingestion of a weight loss supplement containing garcinia cambogia (Garcinia gummi-gata). ${ }^{4}$

We undertook a literature review after searching general internet and PubMed databases for selected terms and combinations of terms, including "adverse event" and "herbal", "complementary and alternative medicine" (CAM) and "Australia", "dietary supplement", "traditional Chinese medicine" (TCM), and "ayurvedic", as well as more specific clinical terms, such as "hepatotoxicity". We examined the range of problems that may be encountered with preparations containing herbal materials, in order to determine the nature of the risks they pose to the Australian public and to make recommendations about their regulation.

\section{Trends in use}

An estimated $70-80 \%$ of the world's population use non-Western medicine in the form of herbal preparations for their primary health care. ${ }^{5}$ The proportion of the Australian population using herbal products as mono- or ancillary therapy increased from $48 \%$ in 1996 to $69 \%$ in $2005,{ }^{6-8}$ with spending on complementary medicine increasing by more than $100 \%$ between 1996 and 2004 . $^{6}$ Similar increases have been reported in many Western countries; in the United States, spending on herbal preparations doubled between 1997 and 2007. ${ }^{9}$

Despite these trends, there have been few recent investigations of the specific problems associated with the use of herbal medicines, and assessments of their safety rely on older studies. About $30 \%$ of American patients use herbal medicines, often without the knowledge of their treating doctor. ${ }^{10,11}$ In Australia, more than half of those using complementary medicine (including herbal products) did not inform their doctors, and they often used such products together with conventional medications. ${ }^{6-8}$ There are a number of reasons for this behaviour, including the belief that herbal preparations are natural products that can be freely combined with pharmaceutical drugs, the desire for a personal therapeutic regime, and a fear of disapproval or

\section{Abstract}

Traditional herbal products are widely used in Australia to treat a broad range of conditions and diseases. It is popularly believed that these products are safer than prescribed drugs. While many may be safe, it is worrying that the specific effects and harmful interactions of a number of their components with prescription medications is not well understood. Some traditional herbal preparations contain heavy metals and toxic chemicals, as well as naturally occurring organic toxins. The effects of these substances can be dire, including acute hepatic and renal failure, exacerbation of pre-existing conditions and diseases, and even death. The content and quality of herbal preparations are not tightly controlled, with some ingredients either not listed or their concentrations recorded inaccurately on websites or labels. Herbal products may also include illegal ingredients, such as ephedra, Asarum europaeum (European wild ginger) and endangered animal species (eg, snow leopard). An additional problem is augmentation with prescription medications to enhance the apparent effectiveness of a preparation. Toxic substances may also be deliberately or inadvertently added: less expensive, more harmful plants may be substituted for more expensive ingredients, and processing may not be adequate. The lack of regulation and monitoring of traditional herbal preparations in Australia and other Western countries means that their contribution to illness and death is unknown. We need to raise awareness of these problems with health care practitioners and with the general public.

ridicule by health professionals. ${ }^{12}$ Access to traditional medicines does not require a prescription, and they are prominently advertised in the popular media.

That side effects of herbal medicines used in traditional societies have not been reported is often cited in favour of their safety, but the lack of systematic observation has meant that even serious adverse reactions, such as kidney failure and liver damage caused by Aristolochia species, were unrecognised until recently. ${ }^{13,14}$ Further, this argument overlooks the potential for serious interactions of herbal preparations with prescription medications, the higher mortality rates in traditional societies, and the effects of globalisation on the content and quality of herbal medicines. The recent Sansom report to the federal Minister for Health made a series of recommendations about the regulation of complementary medicines in Australia, including continued evaluation of ingredients, and permitting the listing on packaging only of ingredients that have been approved for medicinal purposes. ${ }^{15}$

The predominant user group of complementary medicines in Australia comprises younger women (under 35 years old) with a tertiary education. . $^{6,16,17}$ People with chronic diseases or comorbidities such as cancer, diabetes, musculoskeletal disorders or mental illness frequently use complementary medicines. ${ }^{16}$ A study of 10011 Australian women aged 59-64 years found that 39\% of those with menopausal symptoms consulted complementary medicine practitioners, and that $75 \%$ used self-prescribed complementary therapies; ${ }^{18} 53 \%$ of 1037 people with HIV attending 
specialist clinics also used complementary medicines. ${ }^{19}$ As many as $65 \%$ of Australian people with cancer in 2010 used some form of complementary medicine, more than half of whom did so in combination with conventional therapy. ${ }^{20} \mathrm{~A}$ similar finding was made in a study of 4500 Australians aged 50 years or more; $46.3 \%$ of the participants used complementary medicines, of whom $87.4 \%$ used them alongside conventional therapy. ${ }^{21}$ The ten most commonly used herbal preparations in Australia are aloe vera, garlic, green tea, chamomile, echinacea, ginger, cranberry, peppermint, ginseng, and Gingko biloba. ${ }^{22}$ Patterns of use differ according to the medical problem being treated; for example, St John's wort is mainly used to treat depression.

\section{Problems with herbal medicines}

\section{Adulteration with pharmaceutical agents}

Twenty-four per cent of herbal preparations assessed in Taiwan in 1992-1993 included prescription medicines; this figure was quite high, as such augmentation is illegal in Taiwan. ${ }^{23}$ Pharmaceutical agents are still added to herbal preparations, as found in a recent study of TCMs purchased in Australia. ${ }^{1}$ These substances are presumably added to increase the apparent efficacy of the herbal product, reinforcing its authority as a therapeutic alternative. A patient with epilepsy suffered phenytoin poisoning after ingesting a Chinese herbal preparation for seizures that had been augmented with phenytoin, although this drug was not mentioned on the label. ${ }^{24}$ Other pharmaceuticals that have been detected in ostensibly herbal products include antibiotics, antihistamines, corticosteroids, aminopyrine, aspirin, bromhexine, chlordiazepoxide, diazepam, diclofenac, glibenclamide, hydrochlorothiazide, indomethacin, mefenamic acid, paracetamol, phenacetin, phenylbutazone, and theophylline. ${ }^{1,10,25,26}$ In addition to the potential risk of ingesting uncontrolled amounts of these drugs, there are risks of allergies to undisclosed ingredients (such as antibiotics) and of interactions with prescribed medications. There have been reports of Cushing syndrome associated with exposure to undisclosed steroids, aplastic anaemia with exposure to phenylbutazone, and hypoglycaemia with ingestion of glyburide. ${ }^{27,28}$

\section{Substituted plant species}

Replacement of one botanical species with another may be deliberate if the original plant is difficult to obtain or expensive. ${ }^{28}$ One of the better known examples of this practice involved replacement of Stephania tetrandra by Aristolochia fangchi in a weight loss preparation in Belgium; the substituted plant contained the nephrotoxin aristolochic acid, which caused progressive interstitial nephritis, resulting in renal failure in some patients. ${ }^{13}$

Herbal substitution may also be inadvertent if there has been misinterpretation or inaccurate transcribing of the names or formulae in texts. Vernacular names for herbs may differ from region to region, different preparations may have the same name, or one herb may have several names. ${ }^{29}$ All of this can lead to preparation errors; for example, Podophyllum emodi has been used instead of Gentiana species, resulting in serious podophyllin poisoning leading to liver, gut and kidney disease and permanent neurological damage; ${ }^{10}$ Chinese silk vine (Periploca sepium) taken by a mother instead of Siberian ginseng (Eleutherococcus senticosus) caused androgenisation in an infant. ${ }^{30}$

\section{Presence of toxic substances}

Toxic materials from animals or plants may be deliberately added to herbal preparations or can be natural components of the plant species used; for example, aconite root (used in TCM) is poisonous, but can be blended with other herbs to neutralise its toxic effect. ${ }^{10}$ As shown by a case reported in this journal ${ }^{4}$ and another in South Australia that had a lethal outcome despite liver transplantation, ${ }^{31}$ herbal preparations can be hepatotoxic, with significant adverse effects ranging from marked elevation of liver enzyme activity to fatal hepatic failure. These effects may be due to direct liver cell damage caused by plant toxins, or to interactions with prescription medications. ${ }^{14}$ Box 1 lists a selection of conditions and effects associated with certain herbal remedies.

Infants are more vulnerable to the adverse effects of herbal poisoning because of their immature liver detoxification pathways and lower body weight. Chuenlin (Coptis chinensis), given to neonates to "remove toxic products of pregnancy", may cause kernicterus that results in brain damage, as the alkaloid berberine displaces bilirubin from plasma proteins, elevating its free levels in serum. ${ }^{10}$

A toxic animal material knowingly added to traditional medicines is the poisonous secretion of Asian toads (Duttaphrynus melanostictus Schneider and Bufo gargarizans Gantor). ${ }^{34}$ Chan su, used to treat a variety of conditions ranging from skin and throat infections to palpitations, contains toad venom; its active components are bufadienolides that have a digoxin-like effect on the heart, leading to arrhythmias, seizures and coma. ${ }^{26}$ Various herbal preparations are reported to have caused myocardial infarction, congestive cardiac failure, hypotension, hypertension, arteritis, pericarditis, movement disorders, muscle weakness, stroke, and seizures. ${ }^{35,36}$

Heavy metals, including arsenic, lead, mercury, copper, iron, thallium, cadmium, manganese, nickel, and zinc can be essential components of certain traditional medicines. A study of 251 Asian herbal products in California found arsenic in 36 (14\%), mercury in $35(14 \%)$, and lead in $24(10 \%) .{ }^{37}$ A study of TCM products in Australia found excessive levels of lead, cadmium and arsenic in $61 \%$ of preparations. ${ }^{1}$ The levels can be high enough to cause acute mercury and lead poisoning, the latter leading to encephalopathy. ${ }^{10}$ A 5-year-old boy suffered arsenic poisoning when his parents treated a malignancy with a traditional Indian remedy, ${ }^{38}$ while another young boy treated with "Tibetan herbal vitamins" consumed about $63 \mathrm{~g}$ of lead over 4 years. ${ }^{39}$ Preparations can be accidentally contaminated by heavy metals if plants are cultivated in polluted environments or stored in tainted containers. ${ }^{27}$

Traditional herbal preparations may also contain pesticides, including organochlorine preparations and banned substances such as DDT. Other contaminants associated with poor storage

\section{Medical conditions and effects associated with selected herbal preparations ${ }^{12,27,32,33}$}

Condition or effect Preparation

Liver failure Jin bu huan (includes Lycopodium serratum)

Ma huang (Ephedra sinica) Sho-saiko-to Kava (Piper methysticum) Pennyroyal (Mentha pulegium)
Hepatic veno-occlusive disease

Hepatitis Comfrey (Symphytum officinale) Skullcap (Scutellaria laterflora)

Aristolochia species Germander (Teucrium chamaedrys) 
conditions include herbicides, microorganisms, mycotoxins, and insects. $^{27}$

\section{Inadequate processing}

Processing of herbs should ensure removal of unwanted components that may elicit adverse reactions. For example, dried aconite root must be soaked in water and boiled before it is safe to use. Aconite in Chinese herbal preparations has caused poisoning that can lead to lethal cardiac failure and arrhythmia. ${ }^{27}$

\section{Pharmaceutical interactions}

A major area of concern is the potential interaction of herbal medicines with conventional drugs, both prescribed and overthe-counter products. Herbal medicines may enhance or reduce the effects of prescribed medications or elicit unpredictable idiosyncratic effects. Serum drug levels may be increased if their clearance is reduced or their absorption enhanced because of pharmacokinetic interactions. ${ }^{27}$ A selection of potential pharmacological interactions of some herbal preparations with prescription drugs is given in Box 2. This table is not exhaustive. For example, the effects of any drug metabolised by cytochrome P450 3A4 can be affected by St John's wort. While its negative impact on the effectiveness of warfarin is a particular problem, the effect of clopidogrel can be increased, as St John's wort enhances the formation of its active metabolites. ${ }^{46}$

The American Society of Anesthesiologists has suggested that herbal medicines should not be taken for at least 2 weeks before surgery because of possible herb-drug interactions. ${ }^{40}$ Garlic, ginseng and gingko, for instance, all increase the risk of haemorrhage; ginseng also predisposes patients to hypoglycaemia. Echinacea is associated with allergic reactions, and kava and valerian may enhance the sedative effects of anaesthetic agents. Ephedra may cause intra-operative haemodynamic instability by lowering endogenous catecholamine levels, and has been associated with ventricular arrhythmias when halothane is used as general anaesthetic. ${ }^{47}$ Herbal preparations may also alter the results of laboratory tests by interfering with immunoassays. ${ }^{42}$

\section{Auditing, regulation and awareness}

It is likely that the majority of adverse drug reactions and drug interactions associated with alternative medicines are unreported. As noted in several Australian studies, fewer than $50 \%$ of patients discuss their use of herbal preparations with health professionals, ${ }^{6-8}$ and these medicines are rarely recorded on hospital admission forms. The true risks of adopting herbal preparations as a treatment option therefore remain unclear. In Australia, the sale of herbal medicines is profitable ${ }^{6,7}$ and their use is advertised and strongly advocated in popular media, and is not balanced by package warnings ${ }^{48}$ or awareness campaigns about the risks and side effects. The examples we have discussed in this article indicate that some herbal products should carry clear warnings, and highlight the need for a more open debate about claims regarding their efficacy and risks. Guidelines have recently been developed that provide a framework for selecting chemical markers for quality control. ${ }^{49}$

In Australia, all packaged herbal medicines must be placed on the Australian Register of Therapeutic Goods (ARTG) before they are marketed. Medicines are either registered (a product that has been assessed for safety, quality and effectiveness: AUST-R) or listed (lower risk products not evaluated for efficacy: AUST-L). Most herbal medicines are listed products. Listing of products on the
2 Reported pharmacological interactions of common herbal preparations with prescription medicines ${ }^{27,40-45}$

\section{Preparation}

St John's wort (Hypericum

Asian ginseng (Panax ginseng)

Garlic (Allium sativum)

Evening primrose (Oenothera species) and borage (Borago officinalis) oils (contain gamolenic acid)

Dong quai (Angelica sinensis) Devil's claw (Harpagophytum) Ginseng (Panax species) Dan shen (root of Salvia miltiorrhiza) perforatum)
- Interferes with the action of cyclosporine, causing acute transplant rejection

- Causes intermenstrual bleeding in women using oral contraceptives

- Reduces the anticoagulant effect of warfarin

- Reduces the bioavailability of theophylline, amitriptyline, indinavir (HIV-1 protease inhibitor), methadone, and digoxin

- Potentiates the side effects of tricyclic and selective serotonin re-uptake inhibitor (SSRI) antidepressants; can lead to serotonin syndrome

- Reduces the effects of immunosuppressant drugs

- Increases the effects of oral hypoglycaemic agents

- Potentiates the side effects of monoamine oxidase inhibitors

- Has an additive effect with benzodiazepines

- Increases the liver toxicity of paracetamol

- Enhances the effects of oral hypoglycaemic agents

- Increases the incidence of bleeding in patients using anticoagulants

- Lower the seizure threshold in people with epilepsy

- Interfere with the actions of certain anti-epileptic medications, including phenytoin

- Potentiate the action of warfarin
Potential effects

ARTG is based on self-assessment, a system that relies on the honesty of the manufacturer with regard to their composition. Therapeutic Goods Administration (TGA) audits during 2013 and 2014 found that $6-7 \%$ of complementary medicines did not comply with regulations regarding formulation, manufacturing or quality. ${ }^{50}$ With more than one in 20 complementary medicines failing essential composition quality control in Australia, it is clear that more meaningful regulation of the sector is needed. The regulation of complementary medicines was recently reviewed, but the recommendations still retain significant elements of self-assessment. ${ }^{51}$

Further, the presence of AUST-L numbers on herbal medicines can be misleading, as for consumers it implies a higher level of quality control than is accurate. It was recently found that AUST-L TCM products were adulterated with pharmaceuticals and carried inaccurate or misleading ingredient lists. ${ }^{1}$ This shows that, at least for TCMs, the TGA needs to adopt new auditing approaches and to 
prosecute manufacturers who misrepresent the composition of herbal products. Apart from questions of medicinal efficacy, it is reasonable to expect that AUST-L medicines should be tested before and after they are made commercially available, and that products not fit for human consumption be removed from the market. If the status quo is not changed, the public needs to be made more aware that herbal preparations are not effectively regulated and that their use entails a degree of risk.

\section{A new auditing tool kit}

As with food products, it is reasonable to expect that the list of ingredients on the packaging of herbal products is accurate. Auditing of commercial herbal remedies has often been limited to morphologically identifying botanical constituents, which can be almost impossible in heavily processed material. ${ }^{52}$ Obsolete quality control methods are often applied, and many are based on pharmacopoeia entries that have not been updated to reflect recent advances in analytic technology. In many cases, quality control is limited to measuring a single active component; this is inadequate, as a single botanical component may contain several compounds with different pharmacological actions. For example, assessment of St John's wort preparations is typically standardised according to its hyperforin concentration, but this is just one of the hundreds of small molecules that the plant contains.

Until recently, there was no way to comprehensively audit the composition of a herbal product, and it is clear that no single technique can provide the breadth of information needed to fully profile a herbal medicine. However, the recent development of DNA-based approaches has enhanced the capacity to ascertain the ingredients of herbal products, and recent research has discovered that substitution and use of non-declared ingredients are commonplace. The integration of DNA auditing techniques with advanced toxicological and heavy metal analyses can provide effective means for holistically evaluating herbal medicines. By combining several cutting edge technologies, a comprehensive analysis of the composition of herbal medicines sold in Australia is achievable.

Another way to improve auditing is to broaden the understanding of the biochemical effects of these medicines, allowing the prediction of pathological outcomes. Numerous studies have suggested that the "omics" suite of technologies (such as genomics, proteomics and metabolomics) has a significant role to play in investigating herbal preparations. ${ }^{1}$ In particular, metabolomics (a form of advanced, comprehensive biochemical profiling) has the potential to provide detailed information on the composition of herbal products. Combined with in vitro approaches, this may provide the basis for a high throughput screening program for profiling large numbers of herbal products. The combination of latest generation technologies could provide the evidence needed to accurately assess the potential risks posed by herbal preparations.

\section{Conclusion}

While there is no doubt that prescription medications are responsible for many serious side effects and deaths in Australia every year, this should not distract us from trying to determine the contribution of herbal preparations to morbidity and mortality. Although herbal products are claimed (especially on social media sites) to be completely safe, it is difficult to understand why it is widely believed that preparations with biological activity would not also have the potential to cause medicinal side effects. Light touch regulation of the industry means that dosages can be inconsistent, contents inaccurately listed, and toxic and pharmaceutical contaminants and adulterants may be present in herbal medicines.

Rather disturbingly, the answer to the question we asked at the beginning of this discussion - what are the risks to the Australian community from herbal products? - is that we simply do not know. This is a far from satisfactory situation, and perhaps one to which state and federal governments and regulatory bodies, including the TGA, should respond with greater urgency. We would certainly support more widespread testing of products and policing of label and website inaccuracies, although this will require financial support from an already stretched health budget. It may be appropriate for the TGA to require manufacturers to have samples independently tested before placing them on the market. Legal action should be considered in cases of non-compliance with applicable regulations, and preparations containing illegal substances should be banned. How many more adverse drug reactions involving herbal products are needed before more attention is given to this important public health problem?

Competing interests: No relevant disclosures.

Provenance: Not commissioned; externally peer reviewed.

(c) 2017 AMPCo Pty Ltd. Produced with Elsevier B.V. All rights reserved.
1 Coghlan ML, Maker G, Crighton E, et al. Combined DNA toxicological and heavy metal analyses provides an auditing toolkit to improve pharmacovigilance of traditional Chinese medicine (TCM). Sci Rep 2015; 5: 17475.

2 Ernst $\mathrm{E}$. Toxic heavy metals and undeclared drugs in Asian herbal medicines. Trends Pharmacol Sci 2002; 23: 136-139.

3 Braun LA, Spitzer O, Tiralongo E, et al. Naturopaths and Western herbalists' attitudes to evidence, regulation, information sources and knowledge about popular complementary medicines. Complement Ther Med 2013; 21: 58-64.

4 Smith RJ, Bertilone C, Robertson AG. Fulminant liver failure and transplantation after use of dietary supplements. Med J Aust 2016; 204: 30-32. https://www mja.com.au/journal/2016/204/1/fulminant-liver-failureand-transplantation-after-use-dietary-supplements

5 Ernst E. Serious adverse effects of unconventional therapies for children and adolescents: a systematic review of recent evidence. Eur J Pediatr 2003; 162 72-80.

6 MacLennan AH, Wilson DH, Taylor AW. The escalating cost and prevalence of alternative medicine. Prev Med 2002; 35: 166-173.

7 MacLennan AH, Myers SP, Taylor AW. The continuing use of complementary and alternative medicine in South Australia: costs and beliefs in 2004. Med J Aust 2006; 184: 27-31. https://www.mja.com.au/journal/ 2006/184///continuing-use-complementary-andalternative-medicine-south-australia-costs-and

8 Xue CC, Zhang AL, Lin V, et al. Complementary and alternative medicine use in Australia: a national population-based survey. J Altern Complement Med 2007; 13: 643-650.

9 Nahin, RL, Barnes PM, Stussman BJ, Bloom B. Costs of complementary and alternative medicine (CAM) and frequency of visits to cam practitioners: United States, 2007 (National Health Statistics
Reports No. 18). Hyattsville, Md: National Center for Health Statistics, 2009. https://www.cdc. gov/nchs/data/nhsr/nhsr018.pdf (accessed Nov 2016).

10 Chan TYK, Chan JCN. Chinese herbal medicines revisited: a Hong Kong perspective. Lancet 1993; 342: 1532-1534.

11 Brazier NC, Levine MAH. Drug-herb interaction among commonly used conventional medicines: a compendium for health care professionals. Am J Ther 2003; 10: 163-169.

12 Stickel F, Patsenker E, Schuppan D. Herbal hepatotoxicity. J Hepatol 2005; 43: 901-910.

13 Vanhaelen M, Vanhaelen-Fastre R, But P, Vanherweghem J-L. Identification of aristolochic acid in Chinese herbs. Lancet 1994; 343: 174.

14 Pittler MH, Ernst E. Systematic review: hepatotoxic events associated with herbal medicinal products. Aliment Pharmacol Ther 2003; 18: 451-471. 
15 Sansom L, Delaat W, Horvath J. Review of medicines and medical devices regulation - stage two. Report on the regulatory frameworks for complementary medicines and advertising of therapeutic goods. Canberra: Australian Government Department of Health, 2015. http://www.health.gov.au/internet/main/publishing.nsf/ Content/8ADFA9CC3204463DCA257D74000EF5A0/ \$File/Review\%20of\%20Medicines\%20and\%20Medical \%20Devices_Stage\%20Two\%20Report_Accessible.pdf (accessed July 2016).

16 Reid R, Steel A, Wardle J, et al. Complementary medicine use by the Australian population: a critical mixed studies systematic review of utilisation, perceptions and factors associated with use. BMC Complement Altern Med 2016; 16: 176

17 Gartoulla P, Davis SR, Worsley R, Bell RJ. Use of complementary and alternative medicines for menopausal symptoms in Australian women aged 40-65 years. Med J Aust 2015; 203: 146. https://www. mja.com.au/journal/2015/203/3/use-complementaryand-alternative-medicines-menopausal-symptomsaustralian-women

18 Peng W, Adams J, Hickman L, Sibbritt DW. Complementary/alternative and conventional medicine use amongst menopausal women: results from the Australian Longitudinal Study on Women's Health. Maturitas 2014; 79: 340-342.

19 Braun LA, Forrester CA, Rawlins MD, et al. Complementary medicine use by people living with HIV in Australia - a national survey. Int J STD AIDS 2016; 27: 33-38.

20 Clinical Oncology Society of Australia. Position statement. The use of complementary and alternative medicine by cancer patients. Sydney: COSA, 2013. https://www.cosa. org.au/media/1133/cosa_cam-position-statement_final_ new-logo.pdf (accessed July 2016).

21 Morgan TK, Williamson M, Pirotta M, et al. A national census of medicines use: a 24-hour snapshot of Australians aged 50 years and older. Med J Aust 2012; 196: 50-53. https://www.mja.com.au/journal/2012 196/1/national-census-medicines-use-24-hoursnapshot-australians-aged-50-years-and

22 Barnes J, McLachlan AJ, Sherwin CMT, Enioutina EY. Herbal medicine: challenges in the modern world. Part 1. Australia and New Zealand. Exp Rev Clin Pharm 2016; 9: 905-915.

23 Huang WF, Wen K-C, Hsiao M-L. Adulteration by synthetic therapeutic substances of traditional Chinese medicines in Taiwan. J Clin Pharmacol 1997; 37: 344-350.
24 Lau KK, Lai CK, Chan AYW. Phenytoin poisoning after using Chinese proprietary medicines. Hum Exp Toxicol 2000; 19: 385-386.

25 Ernst E. Adulteration of Chinese herbal medicines with synthetic drugs: a systematic review. J Intern Med 2002; 252: 107-113.

26 Dasgupta A. Review of abnormal laboratory test results and toxic effects due to use of herbal medicines. Am J Clin Pathol 2003; 120: 127-137.

27 Byard RW. The potential forensic significance of traditional herbal medicines. J Forensic Sci 2010; 55: 89-92.

28 Zhao Z, Yuen JPS, Wu J, Huang W. A systematic study on confused species of Chinese Materia Medica in the Hong Kong market. Ann Acad Med Singapore 2006; 35: 764-769.

29 Leung AY. Traditional toxicity documentation of Chinese Materia Medica: an overview. Tox Pathol 2006; 34: 319-326

30 Awang DVC. Maternal use of ginseng and neonatal androgenization. JAMA 1991; 266: 363.

31 Gilbert JD, Musgrave I, Hoban C, Byard RW. Lethal hepatocellular necrosis associated with herbal polypharmacy in a patient with chronic hepatitis $B$ infection. Forensic Sci Int 2014; 241C: 138-140.

32 Webb AN, Hardiker W, Cranswick NE, Somers GR Probable herbal medication induced fulminant hepatic failure. J Paediatr Child Health 2005; 41: 530-531.

33 Skoulidis F, Alexander GJM, Davies SE. Ma huang associated acute liver failure requiring liver transplantation. Eur J Gastroenterol Hepatol 2005; 17: 581-584.

34 Kostakis C, Byard RW. Sudden death associated with intravenous injection of toad extract. Forensic Sci Int 2009; 188: el-e5.

35 Ernst E. Cardiovascular adverse effects of herbal medicines: a systematic review of the recent literature. Can J Cardiol 2003; 19: 818-827.

36 Ernst E. Serious psychiatric and neurological adverse effects of herbal medicines - a systematic review. Acta Psychiatr Scand 2003; 108: 83-91.

37 Ko RJ. Adulterants in Asian patent medicines. $N$ Engl $J$ Med 1998; 339: 847.

38 Muzi G, Dell'omo M, Madeo G, et al. Arsenic poisoning caused by Indian ethnic remedies. J Pediatr 2001; 139: 169.

39 Moore C, Adler R. Herbal vitamins: lead toxicity and developmental delay. Pediatrics 2000; 106: 600-602.
40 Awang DVC, Fugh-Berman A. Herbal interactions with cardiovascular drugs. J Cardiovasc Nurs 2002; 16: 64-70.

41 Ernst E. Risks of herbal medicinal products. Pharmacoepidemiol Drug Saf 2004; 13: 767-771.

42 Dasgupta A, Bernard DW. Herbal remedies. Effects on clinical laboratory tests. Arch Pathol Lab Med 2006; 130 521-528.

43 Izzo AA, Ernst E. Interactions between herbal medicines and prescribed drugs: a systematic review. Drugs 2001; 61: 2163-2175.

44 Ernst E. The efficacy of herbal medicine: an overview. Fund Clin Pharmacol 2005; 19: 405-409.

$45 \mathrm{Hu} Z$, Yang X, Ho PCL, et al. Herb-drug interactions: a literature review. Drugs 2005; 65: 1239-1282.

46 Lau WC, Welch TD, Shields T, et al. The effect of St John's wort on the pharmacodynamic response of clopidogrel in hyporesponsive volunteers and patients: increased platelet inhibition by enhancement of CYP3A4 metabolic activity. J Cardiovasc Pharmacol 2011; 57: 86-93.

47 Ang-Lee M, Moss J, Yuan CS. Herbal medicines and perioperative care. JAMA 2001; 286: 208-216.

48 Thakor V, Leach MJ, Gillham D, Esterman A. The quality of information on websites selling St. John's wort. Complement Ther Med 2011; 19: 155-160.

49 Bensoussian A, Lee S, Murray C, et al. Choosing chemical markers for quality assurance of complex herbal medicines: development and application of the Herb MaRS criteria. Clin Pharmacol Ther 2015; 97: 628-640.

50 Therapeutic Goods Administration. Listed complementary medicine compliance reviews [website] Mar 2015. https://www.tga.gov.au/listedcomplementary-medicine-compliance-reviews (accessed May 2016).

51 Sansom L, Delaat W, Horvath J. Expert review of medicines and medical devices regulation. Recommendations. Australian Government Department of Health, 2015. http://www.health.gov.au/internet/main/ publishing.nsf/Content/8ADFA9CC3204463DCA257D74 000EF5A0/\$File/Review\%20of\%20Medicines\%20and\% 20Medical\%20Devices\%20-\%20Recommendations Accessible.pdf (accessed May 2016).

52 Gao W, Yang H, Qi LW, et al. Unbiased metabolite profiling by liquid chromatography-quadrupole timeof-flight mass spectrometry and multivariate data analysis for herbal authentication: classification of seven Lonicera species flower buds. J Chromatogr A 2012; 1245: 109-116. 